

\title{
Aspectos socioculturales del narcotráfico: ayer Medellín, hoy Rosario ${ }^{1}$
}

\section{Socio-cultural aspects of drug trafficking: yesterday Medellín, today Rosario}

\author{
Betina Mariel Bovino² \\ Facultad de Ciencia Política y Relaciones Internacionales. Universidad Nacional de Rosario. Argentina
}

Artículo recibido en abril de 2016; artículo aceptado en junio de 2016

Citación del artículo: Bovino, B. (2016). Aspectos socioculturales del narcotráfico: ayer Medellín, hoy Rosario. I+D

Revista de Investigaciones, 8(2), pp. 46 - 53

\begin{abstract}
Resumen
El poder es parte constitutiva de las redes del narcotráfico. Como en la teoría de los capitales de Bourdieu, donde los diversos tipos de capitales -social, cultural, heredado, económico, cultural- son conmensurables y es posible la conversión de uno a otro, el narcotráfico permite conformar poderes en los campos legitimados, influyendo en los sectores económico, político, social, deportivo y religioso. En este trabajo se abordan los aspectos socioculturales del narcotráfico partiendo de las condiciones estructurales que son a la vez causa y elemento constitutivo del narcotráfico como actor; y se describe el proceso de formación de identidad del narcotráfico y el proceso de institucionalización de la narcocultura en relación a los componentes más importantes de su identidad cultural. A partir de testimonios reales se intentarán poner de manifiesto las formas representativas y los mecanismos legitimadores mediante los cuales el narcotráfico comunica su existencia: sus modos de expresarse, su propia música, sus iconos y sus santos.
\end{abstract}

Palabras clave: identidad, cultura, narcotráfico, imágenes, poder.

\begin{abstract}
Power is a constituent part of the drug trafficking networks. As in the theory of capital of Bourdieu, where different types of capital - social, cultural, legacy, economic, cultural - are commensurable and conversion from one to another is possible, drug trafficking allows to comply powers in legitimate fields, influencing the economic, political, social, sports and religious sectors. This work addresses the sociocultural aspects of drug trafficking on the basis of the structural conditions that are both cause and constituent element of drug trafficking as an actor; and describes the process of formation of identity of drug trafficking and the process of institutionalization of the narcocultura in relation to the most important components of their cultural identity. From actual testimonies is will try to show the representative forms and legitimated mechanisms through which drug trafficking communicates its existence: their modes of expression, its own music, its icons and his saints.
\end{abstract}

Key words: identity, cultural, drug trafficking, images, power.

1. Artículo de reflexión con enfoque cualitativo, resultado de un proyecto de investigación finalizado, perteneciente al curso acreditable de posgrado "Problemática actual en Ciencias Sociales". Doctorado en Trabajo Social. Facultad de Ciencia Política y Relaciones Internacionales. Universidad

Nacional de Rosario (Argentina). Dirección: Riobamba 65 bis. Fecha de inicio: mayo de 2015. Fecha de finalización: octubre de 2015.

2. Licenciada en Trabajo Social. Universidad Nacional de Rosario (Argentina). Doctoranda en Trabajo Social. Docente investigadora de la ciudad de Rosario (Argentina). Dirección: Riobamba 600 bis. betibovino@hotmail.com 
Hace ya bastante tiempo que vivimos en una sociedad mundial: no hay ningún país ni grupo que pueda vivir al margen de los demás. Esta sociedad mundial se puede comprender como una pluralidad sin unidad. Siguiendo a Beck (1998), la globalización abarca los procesos en virtud de los cuales los Estados nacionales soberanos se entremezclan e imbrican mediante actores transnacionales y sus respectivas probabilidades de poder, orientaciones, identidades y entramados varios. Dicha globalidad se torna irrevisable por las siguientes razones:

- El ensanchamiento del campo geográfico y la creciente densidad del intercambio internacional, así como el carácter global de la red de mercados financieros y del poder cada vez mayor de las multinacionales.

- La revolución permanente en el terreno de la información y las tecnologías de la comunicación.

- La exigencia, universalmente aceptada y considerada como el principio de la democracia, de respetar los derechos humanos.

- La política mundial posinternacional y policéntrica: junto a los gobiernos hay cada vez más actores transnacionales con cada vez mayor poder (multinacionales, organizaciones no gubernamentales, Naciones Unidas).

- El problema de la pobreza global.

- El problema de los daños y atentados ecológicos globales.

- El problema de los conflictos transculturales en un lugar concreto.

Las fronteras ya no pueden funcionar tan eficientemente como "containers" de poder porque en la globalización "el dinero, las tecnologías, las mercancías, las informaciones traspasan las fronteras, como si éstas no existieran" (Beck, 1998, p. 14 ). Personas e ideas que los gobiernos mantendrían fuera del país (drogas, emigrantes ilegales, críticas a sus violaciones de los derechos humanos) consiguen introducirse.

En 1995 en la Cumbre de Copenhague, la Organización de las Naciones Unidas reconoce la necesidad de contar con un enfoque integral de las condiciones sociales ante el abrumador avance de los procesos globalizantes; procesos que redundan en la redistribución de privilegios y despojos, riqueza y pobreza, recursos y desposesión, poder e impotencia, libertad y restricción.

Entre los componentes de estos procesos globalizantes "se incluyen los efectos de las innovaciones tecnológicas, la exclusión social, la inequidad en la disponibilidad y el consumo, la fragmentación social, el crecimiento de la violencia y el surgimiento de nuevas formas de agresividad social, el narcotráfico y el consumo creciente de drogas entre los mas jóvenes, la pérdida de identidad" (Francisco, 2015, p. 35).

\section{Narcotráfico: su legitimación}

El narcotráfico surge y se desarrolla como crimen organizado transnacional de enormes dimensiones, que va produciendo y se va identificando con una constelación integrada por una economía criminal, una microsociedad, una narcocultura y una narcopolítica que apunta al Estado mismo.

Por eso es necesario considerar al narcotráfico como una producción y comercialización de bienes y servicios ilegales, que podría caracterizarse como "capitalismo mafioso" y que ha provocado una restructuración económica, política y social.

Los recursos destinados a la producción y comercialización de productos ilegales tanto a escala nacional como internacional representan un importante monto de capital dinero, que no solo proviene de naciones atrasadas o de las sociedades industrializadas. Tal como lo ha evidenciado Palacios (1999), "se puede presumir que numerosos sectores de capitalistas dedican importantes cantidades de capital a la producción y venta de drogas. Junto a esta compleja organización se desarrolla una enmarañada red de poderes que se insertan en las tramas de estados y sociedades." (p. 32).

Se logra así una fuerte presencia en las economías nacionales a las que se irriga y controla; se modifican fuerzas y estructuras socioeconómicas; se multiplican consecuencias directas e indirectas; se trasmuta el poder económico y financiero en poder social, cultural, ideológico, político y militar para la defensa y el ataque.

Transcurrían los años setenta, y América Latina se teñía de sangre y muerte: dictaduras militares, torturas, crímenes de lesa humanidad, terrorismo de Estado. Eran los años en que el llamado peligro comunista, según la visión estadounidense, acechaba a Latinoamérica infiltrándose en sectores de la sociedad de los distintos países dando lugar a movimientos de protesta y a guerrillas. El narcotráfico como fenómeno emergente, tal como lo plantea Rossi (2006), empezó a cobrar visibilidad en esa época y en su formación y crecimiento confluyeron distintos factores. Se convirtió en el enemigo que usaba sustancias como instrumentos para minar y destruir los 
fundamentos mismos de la civilización norteamericana con sus valores y cultura. Por encontrarse las grandes organizaciones narcotraficantes más allá de las fronteras norteamericanas, en el sur del continente, el narcotráfico asumió la caracterización de enemigo externo.

\section{El cartel de Medellín}

Concretamente en Colombia, los carteles se formaron en torno al tráfico de drogas. El contexto geográfico y la herencia dejada por la historia jugaron un papel esencial en la aparición de la organización criminal más importante de Colombia: el cartel de Medellín.

Medellín es la capital del departamento de Antioquia (que significa "Montaña de oro") cuya salida al Caribe fue escenario, desde la conquista española, de actividades ilegales que iban desde la piratería al contrabando. La prosperidad de Medellín, fundada hace dos siglos, se basó sucesivamente en la actividad minera, el tabaco, el café, el banano y el petróleo. Una recesión en los años sesenta llevó a los terratenientes de la zona a apostar a la marihuana. Pero cuando el boom de esta droga llegó a su fin, aparecieron en escena un puñado de individuos -Pablo Escobar y su familia, los hermanos Ochoa, Carlos Lehder y Rodríguez Gacha- "diestros en las prácticas del contrabando y del robo organizado, e impregnados por el espíritu de empresa propio de las elites urbanas de Medellín y su región" (Labrousse, 2011, p. 46).

El rápido crecimiento económico y la fuerza del narcotráfico, así como la constitución de sus redes y su percepción sociocultural en los espacios locales, nacionales y transnacionales, ha propiciado que estos carteles del narcotráfico se hayan convertido en actores que participan de las estructuras de poder en el sistema internacional, con claros efectos en la cultura; esto como resultado de un largo proceso de acciones y hábitos recurrentes construidos por traficantes de droga que, conforme adquirían mayor dominio en el negocio, fueron conquistando los círculos dirigentes de la política, logrando ascenso social y aumentando sus redes de control y legitimación social.

\section{Como refiere Salazar (2001):}

Pablo Escobar era un hombre con talante de estadista. Terminó una guerra en diez minutos. Me pareció un hombre al que le cabía el país en la cabeza. Meterse en Moravia, el famoso cerro donde la gente vivía encima de la basura, para llevarlos a un barrio con todas las de la ley, era un hecho político que todo el país tenía que conocer. Pablo no tenía la apariencia del hombre malo; era bonachón, parecía, para llamarlo en términos de la época, un ba- cán. Por lo general un hombre humilde cuando llega a tener plata y poder se desboca, se deshace en ostentación. Pero a él no le vi lucir siquiera ni una cadena ni un anillo; vestía con ropa costosa pero discreta. A mí me llamaba la atención y me daba risa la importancia que le daba a su peinado (p. 42).

De manera que la transnacionalización del narcotráfico ha implicado el desarrollo de una narco-cultura, definida como un conjunto de rasgos (comportamientos y valores, lenguaje, códigos propios, normas, simbolismos y significados) relacionados con la producción, distribución y venta de drogas; esta implica, siguiendo a Astorga (2010) un modo de vida, un modo de pensar y un modo de ver el mundo. La cultura se refiere al patrimonio intelectual y material de una sociedad o grupo determinado, es el conjunto de conocimientos, valores, creencias, normas, símbolos y modelos de comportamiento que los miembros de dicho grupo comparten en diversa medida; siguiendo a Valenzuela (2002) la cultura abarca todas las manifestaciones de los hábitos sociales del grupo, los productos de la actividad humana inducidos por estos hábitos, y los medios materiales para su producción y reproducción.

La temática del narcotráfico no es un hecho simplemente delictivo y por lo tanto un asunto policial. Es la manifestación intrínseca de un sistema bajo signos contrapuestos y complementarios que caracterizan la globalización.

Como describe Wallace (1993), Pablo Escobar no dejó gobernar a tres presidentes. Transformó el lenguaje, la cultura, la fisonomía y la economía de Medellín y del país. Antes de Pablo Escobar los colombianos desconocían la palabra narcotráfico. Antes de Pablo Escobar Medellín era considerada un paraíso. Antes de Pablo Escobar, el mundo conocía a Colombia como la Tierra del Café. Y antes de Pablo Escobar, nadie pensaba que en Colombia pudiera explotar una bomba en un supermercado o en un avión en vuelo. Por cuenta de Pablo Escobar hay carros blindados en Colombia y las necesidades de seguridad modificaron la arquitectura. Por cuenta de él se cambio el sistema judicial, se replanteó la política penitenciaria y hasta el diseño de las prisiones, y se transformaron las Fuerzas Armadas. Pablo Escobar descubrió, más que ningún antecesor, que la muerte puede ser el mayor instrumento de poder.

El narcotráfico se ha expandido en un contexto que ha permitido su fortalecimiento como industria, en el marco de una intensa producción y emisión de significaciones construidas históricamente que tienden hacia la justificación implícita y la promoción de ciertas facetas de la actividad. En primera instancia, siguiendo a Simonett 
(2004), el narcotráfico tiene una elevada correlación con la pobreza, y aunque no es esta su única causalidad, es evidente que las condiciones socioeconómicas han sido determinantes en la incorporación al negocio de sujetos provenientes de sectores arruinados o empobrecidos, estratos populares y marginados con un bajo nivel de instrucción.

La rapidez con que los narcotraficantes adquieren los recursos se ha convertido según Kaplan (1992) en la esperanza de salida de las condiciones deprimidas, sumergidas, de ascenso social y de participación en los beneficios de lo que pueda haber de crecimiento y modernización. Ciertamente, el narcotráfico ha sido identificado como un actor cuya irrupción ha adquirido mayor fuerza, capacidad expansiva y proyección en las estructuras de poder (producción, finanzas, seguridad y conocimiento); así también, como una organización altamente lucrativa, que se ha ido legitimando en el marco de la economía, la sociedad y la política. Aparece como portador de nuevas variables: no ya simplemente cuerpos escasos o numerosos, sometidos o sumisos, ricos o pobres, útiles o inválidos, vigorosos o débiles, como evidencia Foucault (1985), sino también más o menos utilizables, más o menos susceptibles de inversiones rentables, dotados de mayores o menores probabilidades de supervivencia, de muerte o enfermedad, más o menos capaces de aprendizaje eficaz.

Allí donde la vulnerabilidad cultural, el consumismo, el hedonismo, el instrumentalismo y la búsqueda incesante de prestigio social se entrecruzan con estos marcos legitimados por el poder del narcotráfico, surge la narcocultura, "cosechando adhesiones en medio de una profunda crisis en la que las sociedades están inmersas, donde valores, contravalores o ausencia de valores, por parte, sobre todo, de los jóvenes, para los cuales el futuro se ha desdibujado convirtiéndose en un no futuro y cuyas consecuencias directas se expresan en el nada vale, por lo tanto todo vale, en el tener para ser" (Rossi, 2007, p. 16).

El corrido es una forma musical y literaria popular. En sus inicios se le llamaban simplemente corridos de tráfico de drogas ilícitas. En la medida en que la temática abarcó más allá de los peligros y las hazañas, cambió a canción exaltadora de la vida ostentosa y placentera del narcotraficante y pasa a denominarse narcocorrido. En esencia, los narcocorridos conservan parte de la estructura de los corridos tradicionales, por lo que se considera que son una evolución de estos y no precisamente un nuevo género musical, con excepción de las temáticas cantadas. En sus narrativas dan cuenta de la violencia, el poder, la muerte, el consumo suntuoso y los placeres derivados de las acciones del narcotraficante. Los personajes del nar- cocorrido conservan ciertos elementos del papel otorgado al héroe del corrido tradicional: son carismáticos, dispuestos a enfrentar situaciones de peligro, a arriesgar su vida, ponen a prueba la lealtad y el valor siempre al margen de la ley, son benefactores de su pueblo y en correspondencia reciben su protección; sin embargo, no dejan de ser personajes violentos, corruptos y asesinos. Vemos entonces una ilegalidad contemporánea representada por el narcotráfico, la cual produce y difunde su propia expresión por ejemplo a través de la música.

Dicha narcocultura dice que para salir de pobre y tener poder, todo vale: subir a las que sea y como sea, sin respetar leyes, reglas, instituciones, valores, cuerpos, éticas, vidas: un modo de pensar que se convierte en una estética - ética.

En efecto, el apoyo de las poblaciones a los narcotraficantes ilustra la sólida integración simbólica del narcotráfico a la sociedad y el estrecho vínculo, condicionado por el dinero, entre este y los grupos excluidos y castigados, que de alguna manera los enfrenta al Estado y consigue lealtad hacia el narcotraficante. Pablo tenía su oficina en el sector de El Poblado y empezó a ganar notoriedad por sus obras sociales. Medellín, que crecía desmesuradamente, se tragó a Envigado y otros municipios vecinos. El río que atraviesa el valle se volvió oscuro y de aguas podridas. La industria, ante la competencia del contrabando y la obsolescencia tecnológica, entró en decadencia, y miles de obreros fueron arrojados a las calles. Las montañas se siguieron poblando de pobres ajenos de la economía formal y del Estado, y cada vez más distantes de los poderes tradicionales y del catecismo católico que ordenaba resignación y sumisión. Esos pobladores, descreídos de los partidos políticos tradicionales, solo se ligaban a ellos por pírricos beneficios provenientes de un manejo clientelista de los recursos del Estado. Pero tampoco habían encontrado en la izquierda y las guerrillas una opción. En esas montañas, habitadas por desposeídos, que recorría en un Renault 18 habano, Pablo inició las obras sociales que le darían por siempre entre los humildes fama de hombre bondadoso, según Salazar (2001).

Las representaciones sobre el narcotráfico recreadas en las formas objetivadas de la narcocultura no solo sirven para dar sentido a una serie de elementos que la sociedad conoce o intuye, sino que participan en la producción de pautas culturales a su alrededor, por lo tanto, permiten comprender las formas en que el narcotráfico irrumpe en las sociedades y el modo en que estas aprehenden su presencia como un nuevo actor. Un actor que ha podido emerger en terreno fértil: en escenarios complejos, inciertos, caóticos, en malestares que sepa- 
ran unos sujetos de otros, que estimulan los deseos y necesidades individuales. Un actor que es asumido cada vez más como parte de la cotidianidad en las sociedades latinoamericanas, cuya popularidad en los medios y la cultura popular indican que forma una parte destacada de la realidad social.

Según Sennet (2003), las imágenes clasifican: hay quien pertenece al retrato del grupo; hay quien no. Las antiguas leyes de Estados Unidos que afirmaban que una gota de sangre negra bastaba para que una persona fuera negra son un extremo de esa clasificación, en la que una piel de color imponía una identidad total.

La narcocultura pone a disposición social (para su institucionalización) imágenes: soldadito, narcotraficante, sicario, adicto, carteles. Estas no son solo imágenes identificadas por el conjunto social, sino que pasan a ser categorías sociales objetivadas en un lenguaje, que no es solo instrumento de comunicación sino también expresión de un pensamiento y es el intermediario que conduce a la comprensión e interpretación de los sentidos. Aparece así un discurso que se convierte en la forma de expresar ese lenguaje.

La gente asistía por miles a los actos en que se echaba un discurso, así lo evidencia Salazar (2001):

A nosotros nos interesaba aprovechar esa plataforma para que la gente conociera nuestro proyecto, así fuera expuesto por otra persona. Él decía: yo monté un autobús en 28 años y por tanto yo soy de ustedes, yo soy de aquí, ténganme como uno de ustedes y vengo aquí porque las condiciones económicas han cambiado y vengo a compartir con ustedes lo mío, a compartir con ustedes el derecho que tenemos a vivir dignamente. Que hagamos todo lo que podamos hacer para que la juventud no entre en el vicio de la droga (p. 184).

Las pautas consumistas y suntuarias de los narcotraficantes, el mantenimiento o aumento del empleo y del ingreso de sus dependientes como servidores y súbditos en relaciones clientelistas, generan o refuerzan una proliferación de actividades comerciales y profesionales para satisfacer la demanda de bienes y servicios de los mas variados tipos. La narcocultura se manifiesta en la ideología y en las representaciones sociales que se reflejan en los comportamientos y las actitudes individuales, grupales $y$ colectivas (creencias, valores y pensamientos traducibles en obras, artefactos simbólicos y construcciones significativas). Por otra parte, se manifiesta en el lenguaje, el habla, los gestos, los hábitos, la moda, la vestimenta y accesorios, los artículos de consumo y estatus, en la músi- ca, la literatura y la iconografía popular. Ambas condiciones o formas, las internalizadas/subjetivas y las objetivas de la narcocultura, representan aspectos fundamentales.

El narcotraficante generalmente profesa una religiosidad popular muy fuerte, particularmente hacia determinados santos que son asociados a la tradición católica, y otros que han sido producto de un proceso controversial de santificación como Jesús Malverde, el santo de los narcotraficantes. El culto a Jesús Malverde se extiende a lo largo del noroeste de México, Los Ángeles, y Medellín; este, un ladrón generoso que ayudaba a los pobres, aparece actualmente como una de las formas alternas de la santidad en el imaginario popular: un santo folclórico que conlleva el aspecto de criminalidad. En este sentido, la figura de Malverde interviene en el imaginario del narcotraficante vinculando el acto de devoción como manifestación cultural y una realidad sociopolítica asociada al narcotráfico que pone a disposición una imagen de santo que es compatible con la condición humana imperfecta. La fe al Niño de Atocha (que libera perseguidos arbitrariamente por la justicia, cura enfermos y llena de riqueza a los pobres) marcó la vida de Pablo Escobar, pero también la imagen de Madre-Virgen es sagrada, ella es sinónimo del amor, la entrega y la adversidad. Al santuario de María Auxiliadora, la Virgen de los Sicarios, acudían desde todos los rincones colombianos a pedirle que sus empresas tuvieran éxito. En retribución le encendían velas, le rezaban, le escribían cartas, comulgaban, se confesaban y daban diezmos (generosas limosnas). En una nota del diario El Tiempo (1994) de Colombia, un feligrés recuerda unas palabras de FernandoVallejo:

La Virgen de Sabaneta hoy es María Auxiliadora, pero no lo era en mi niñez: era la Virgen del Carmen y la parroquia la de Santa Ana. Hasta donde entiendo yo de estas cosas, María Auxiliadora es propiedad de los salesianos, y la parroquia de Sabaneta es de curas laicos. ¿Cómo fue a dar María Auxiliadora allí? No sé. Cuando regresé a Colombia la encontré entronizada, presidiendo la iglesia desde el altar de la izquierda, haciendo milagros. Un tumulto llegaba los martes a Sabaneta de todos los barrios y rumbos de Medellín adonde la Virgen a rogar, a pedir, que es lo mejor que saben hacer los pobres. Y entre esa romería tumultuosa los muchachos de la barriada, los sicarios. Ya para entonces Sabaneta había dejado de ser un pueblo y se había convertido en un barrio más de Medellín, la ciudad la había alcanzado, se la había tragado; y Colombia, entre tanto, se nos había ido de las manos. Éramos, y de lejos, el país mas criminal de la tierra, y Medellín la capital del odio. Pero estas cosas no se dicen, se saben. Con perdón. 
Por su parte, en Un narco se confiesa y acusa, Fabio Ochoa (1989) se describió así:

En verdad siendo traficante no me considero delincuente ni pecador. A nadie he matado ni mandado asesinar. A nadie he robado ni secuestrado. Mucho menos extorsionado o chantajeado. No me he quedado con los ahorros de nadie. He pagado mis deudas. No realizo chanchullos o negocios con el gobierno. Pago impuestos. Hago obras de caridad. Voy a misa. Cumplo con mis obligaciones familiares. Reconozco buenos salarios a mis trabajadores. Colaboro con la política sin exigir un puesto para nadie. Creo además en el sistema democrático. Inclusive, admiro la sociedad norteamericana, en muchos aspectos, menos en su doble moral y en la discriminación hacia colombianos y latinos (p. 41).

Las diarias y majestuosas fiestas financiadas con el dinero de sus actividades ilegales permiten vinculaciones y reconocimiento público; esta relación entre ganancia y gasto adquiere un carácter paradójico: el traficante es consciente de sus pecados, pero debe pecar para conseguir el dinero que le facilitará el acceso a otras formas de vida, el dinero de la droga se exhibe en grandes y lujosas residencias, autos de lujo, alhajas llamativas, fiestas estruendosas, beepers y celulares. A todo ello se agregan, en palabras de Kaplan (1992), numerosos ejemplos de escándalos donde se mezclan mujeres, drogas, y alcohol.

Los grandes capos de la droga desempeñan roles sustitutivos del llamado Estado benefactor. Para la captación y manipulación sobre todo sectores medios y populares, los narcos aparecen como mecenas:

Me angustió siempre ver en los barrios populares a los niños y jóvenes exponiendo su vida al correr detrás de un balón por las calles cruzadas de raudos automotores - decía Pablo Escobar-. Soñaba con el día en que esta juventud tuviera estadios propios para poder jugar sin humillarse ante nadie ni exponerse a un accidente. Así nació mi vocación por la creación de los campos deportivos. Hoy construimos canchas para fútbol, basketball, voleibol y polideportivos, ojalá mañana podamos extender nuestra acción para campos de beisbol, piscinas y gimnasios a montón, para el pueblo. (Salazar, 2001, p. 94)

Reparten entre los pobres, en colonias y reuniones sociales o políticas, dinero y bienes de consumo; apoyan la construcción de viviendas de bajo costo en suburbios y ciudades perdidas; contribuyen al mejoramiento de lugares públicos y a la conformación de centros recreati- vos, y participan en actividades deportivas. Esta intensa y variada injerencia permite a los grandes narcos el logro simultáneo de popularidad, inversiones lucrativas, facilidades para el tráfico de cocaína y el blanqueo de capitales, contactos y entrelazamientos con grupos del establishment nacional.

Hago público mi definitivo y total retiro de la política. Decisión ésta que adopté desde el mes de septiembre del año pasado, que es inmodificable y lo ratifico no obstante el caudaloso plebiscito de solidaridad que me ha llegado de todos los municipios y de los barrios populares de Medellín. Seguiré en lucha franca contra las oligarquías y las injusticias, y contra los conciliábulos partidistas, autores del drama eterno de las burlas al pueblo, y menos aún los politiqueros: indolentes en esencia ante el dolor del prójimo y arribistas de siempre cuando se trata de la partija burocrática. Por ello mismo me duele el deprimente contraste de los que nada tienen frente a los que sólo entienden por exclusiva divisa de sus vidas el acumular capital, oportunidades y ventajas, que lejos están de cumplir función social alguna. Bien establezco ahora la enorme diferencia entre mis 17 años de ardua e infatigable lucha cívica, frente a los escasos meses de mi activa participación en política, a la cual me entregue integro pensando que a través de ella podrían canalizarse muchos factores y recursos a favor del pueblo. Para finalmente concluir que los apremios y dolencias populares están distantes de la sensibilidad de los políticos cuyas egoístas miras sólo se encuentran fijas en retocar sus deterioradas imágenes narcisistas y acrecentar sus tambaleantes feudos podridos. (Salazar, 2001, p. 147).

\section{Rosario: un puñado de rosas}

En la ciudad de Rosario, Argentina, un número creciente de grupos, sectores, procesos, espacios y circuitos, son incorporados a la órbita del tráfico y sus organizaciones. Son especializados en la producción de la materia prima y en la elaboración industrial de las drogas, el transporte y las comunicaciones, la distribución, la comercialización, la violencia de autoprotección y agresión, la prestación de servicios conexos, el lavado de dólares, las reinversiones ilícitas, las nuevas inversiones en la economía formal. Rosario (un puñado de rosas, como lo indica etimológicamente su nombre) pasó a convertirse en el lugar de producción, tránsito, consumo, y lavado de dinero de drogas que, con el tiempo y el cambio de situaciones, pueden reasignarse y recombinarse de manera diferente. 
Para la necesaria revisión y el reajuste de la estrategia y la política, que asegure un aumento de su eficacia y una preparación de sus posibilidades de triunfo en la lucha contra el tráfico, es indispensable ante todo descartar todo lo que sea o implique un enfoque restrictivo, con sus sesgos, rigideces y simplificaciones. Se requiere, por el contrario, un enfoque totalizador y dinámico, que no deje de tener siempre presente la naturaleza de la adicción y del tráfico de drogas, con sus realidades, sus lógicas, sus movimientos. No se debe ignorar que una y otro se dan en un contexto (socioeconómico, cultural, político, jurídico, institucional) que es además, y al mismo tiempo, nacional e internacional. No pueden dejarse de lado las causas y los efectos y síntomas de estos fenómenos, la multidimensionalidad (economía criminal, micronarco sociedad, narcocultura, narcopolítica), lo coyuntural y lo estructural, la oferta y la demanda, la represión y la prevención y rehabilitación. Análisis, diagnósticos y alternativas deben tomar en cuenta, además, los tres grandes aspectos/niveles del problema: el Estado y las sociedades nacionales, la cooperación bilateral y la cooperación multilateral o internacional.

Así, los cambios sociales y culturales que el narcotráfico ha generado en varios países y regiones de Latinoamérica fueron sintetizados en pautas e imágenes claras que dan razón de la existencia de un actor que ha sido acogido económica y culturalmente por las naciones, regiones y localidades en las que se asienta, evidenciado en este proceso que la cultura no solo causa, sino también constituye agentes, en función de las propiedades e interacciones de personas con existencia independiente.

La presencia y el fortalecimiento del narcotráfico no pueden darse en ningún país sin la complicidad de autoridades estatales de distinto nivel y de diferentes sectores civiles o militares.

Los narcos van creando estrechas vinculaciones con policías, jueces, políticos, gobernantes, funcionarios, legisladores, magistrados y militares, como lo plantea Astorga (2010). En el caso del narcotráfico, también en Rosario, no se trata de un poder paralelo enfrentado al Estado, sino de una interdependencia estructural entre ciertas instituciones que ha dado lugar a una estructura de poder en el interior mismo del Estado.

\section{Referencias}

Astorga, L. (2010). "México: de la seguridad a la inseguridad en la transición democrática." En Maihhold Günter y Jost Stefan (Eds.) El narcotráfico y su combate. Sus efectos sobre las relaciones internacionales. México: Sitesa.
Beck, U. (1998). ¿Qué es la globalización? Falacias del globalismo y respuestas a la globalización. España: Paidós. Emmerich, N. (2015). Geopolítica del narcotráfico en América Latina. México: IAPEM.

Foucault, M. (1985). Saber y Verdad. España: La Piqueta. Francisco.Vaticano II. Encíclica Laudato Si'. 24 de mayo, 2015.

Kaplan, M. (1992). Aspectos sociopolíticos del narcotráfico. México: Instituto Nacional de Ciencias Penales.

Labrousse, A. (2011). Geopolítica de las drogas. Buenos Aires: Marea.

Nullvalue (1 de mayo de 1994). En los subfondos de Medellín. El Tiempo. Recuperado de http://www.eltiempo. com/archivo/documento/MAM-113440

Ochoa, F. (1989). Un narco se confiesa y acusa. Medellín: Colombia Nuestra.

Palacio, G. (1999). La irrupción del paraestado. Ensayos sobre la Crisis colombiana. Bogotá: ILSA-CEREC.

Rossi, A. (Marzo, 2006). Minacce asimmetriche e militarizzazione in America Latina. Giano, Roma, XVIII (52), 34-42.

Rossi, A. (2007). "Drogas y narcotráfico". Cuadernillo Seminario I Facultad de Ciencia Política y Relaciones Internacionales. 15-26.

Salazar, A. (2001). La Parábola de Pablo. Auge y caída de un gran capo del narcotráfico. Colombia: Planeta Colombiana.

Sennett, R. (2003). El espejo. Nueva York: Anagrama.

Simonett, H. (2004). En Sinaloa nací: Historia de la Música de Banda. México: Asociación de Gestores del Patrimonio Histórico y Cultural de Mazatlán.

Valenzuela, J. M. (2002). Jefe de jefes. Corridos y narcocultura. México: Plaza y Janés.

Wallace, A. (2003). La batalla final. Revista Semana. (605), 12-18. 